\title{
Kernos
}

Revue internationale et pluridisciplinaire de religion grecque antique

4 | 1991

Varia

\section{Mentor. Consultation de la base de données}

\section{(2) OpenEdition \\ Journals}

Édition électronique

URL : http://journals.openedition.org/kernos/528

DOI : $10.4000 /$ kernos.528

ISSN : 2034-7871

\section{Éditeur}

Centre international d'étude de la religion grecque antique

Édition imprimée

Date de publication : 1 janvier 1991

Pagination : 365-366

ISSN : 0776-3824

Référence électronique

"Mentor. Consultation de la base de données », Kernos [En ligne], 4 | 1991, mis en ligne le 06 avril 2011, consulté le 02 mai 2019. URL : http://journals.openedition.org/kernos/528 
Kernos, 4 (1991), p. 365-366.

\section{MENTOR}

\section{BIBLIOGRAPHIE CRITIQUE INFORMATISÉE DE LA RELIGION GRECQUE ANTIQUE}

\section{Mise en service de la banque de données}

La banque de données peut être d'ores et déjà consultée pour les publications parues entre 1945 et 1985 (6000 références). Pour la période antérieure, le travail d'analyse est en cours, mais les références sans commentaire critique peuvent être obtenues. Un guide bibliographique sélectif couvrant la période antérieure à 1986 paraîtra dans le courant de l'année 1991 et sera suivi de suppléments. Plus de 130 chercheurs, issus d'une quinzaine de pays, participent au programme. Les notices sont signées par les auteurs.

\section{Domaine couvert}

La période prise en compte va des origines préhistoriques au VIe siècle de notre ère. Le domaine de la religion grecque est traité dans toute son ampleur: vocabulaire religieux; croyances, mythes et symboles; sentiment religieux; culte, fêtes et rites; aspects politiques, sociaux, juridiques, économiques et militaires; rapports avec les arts, la littérature et la philosophie; religions en contact; études comparatives; survivances.

\section{Structuration de la documentation et instruments de consultation}

Pour interroger la banque de données, on dispose de plusieurs instruments :

Organon : ensemble de rubriques préalablement établies et codées, offrant une vision générale et hiérarchisée des différents aspects de la religion grecque.

Thesaurus : index alphabétique de mots-clés correspondant à des sujets ponctuels (noms propres, notions, realia, etc.). Il comporte à ce jour plus de 2.000 entrées, dont les principales sont subdivisées.

Un code chronologique permet éventuellement de sélectionner la période choisie. La banque de données peut être aussi interrogée à partir 
des éléments des références bibliographiques (noms d'auteur, dates de publication).

\section{Modalités pratiques d'interrogation}

En attendant d'être relié aux réseaux informatiques internationaux, Mentor peut être consulté soit par une visite sur place, soit par téléphone, soit par correspondance. Pour formuler adéquatement les questions et exploiter au mieux les ressources de la documentation rassemblée, il est vivement conseillé de se procurer le Guide d'information qui comprend notamment l'Organon et le Thesaurus. Ce guide peut être commandé, au prix de $250 \mathrm{FB}$ (63 pages; frais de port compris; facture jointe à l'envoi) à l'adresse ci-dessous. Le coût de l'interrogation comprend un forfait de $100 \mathrm{FB}$, plus $10 \mathrm{FB}$ par référence obtenue avec notice critique ou 5 FB sans notice. Frais de port en sus.

Adresse du programme Mentor

André MOTTE et Paul WATHELET, directeurs

Vinciane PIRENNE-DELFORGE, secrétaire scientifique

Université de Liège

Place du XX-Août 32

B - 4000 Liège

Belgique

Tél. : (0)41/66.55.68 ou 66.55.97. 